\title{
Lightweight Self-Compacting Concrete Incorporating Industrial Rejects and Mineral Admixtures: Strength and Durability Assessment
}

\author{
P. O. Awoyera ${ }^{1}$ (D) - I. I. Akinwumi ${ }^{1}$ • V. Karthika ${ }^{2} \cdot$ R. Gobinath ${ }^{3} \cdot$ R. Gunasekaran ${ }^{2} \cdot$ N. Lokesh ${ }^{2} \cdot$ M. Manikandan ${ }^{2}$. \\ T. Narmatha ${ }^{2}$
}

Received: 20 May 2019 / Accepted: 24 September 2019

(C) Springer Nature B.V. 2019

\begin{abstract}
By the recent global research developments, a lot of natural and artificial materials that are normally discarded and landfilled, are continually investigated for potential construction applications. In this study, the mechanical and durability properties of lightweight self-compacting concrete produced using pumice, ground granulated blast furnace slag (GGBS), rice husk ash (RHA) and precipitated silica, was investigated. A detailed experimental design was performed, which entailed reducing the water powder ratio, and use of viscosity modifying admixture, for enhancing the fresh SCC quality. The experimental process involved assessment of mechanical and durability properties of concrete mixtures. The results have shown that compressive and flexural strength of SCC made with lightweight aggregate are improved using mineral blended cement. Also, same mix, but with pumice as coarse aggregate gave higher split-tensile strength than other mixtures. This study deduced that pozzolanic reactivity and filler action of supplementary cementitious materials used, enhanced the resistance of the mixtures to deterioration when exposed to aggressive environment.
\end{abstract}

Keywords Durability $\cdot$ Mix design $\cdot$ Strength properties $\cdot$ Supplementary cementitious materials $\cdot$ Sustainability

\section{Introduction}

Self-compacting concrete (SCC), a highly flow able and stable concrete composite, is well accepted all over the world for several types of construction projects. In its uniqueness as compared to other types of concrete, SCC does not require vibration force during placement and compaction, yet it flows under its own weight, without having signs of segregation or bleeding.

In the design of SCC, a relatively low yield value must be ensured for its properties to be achieved. That is, SCC designs should consider its deformability or stability. Generally, the properties of SCC are achieved by decreasing the coarse

P. O. Awoyera

paul.awoyera@covenantuniversity.edu.ng

1 Department of Civil Engineering, Covenant University, Ota PMB 1023, Nigeria

2 Department of Civil Engineering, Jayshri Ram Group of Institution, Tamilnadu, India

3 S R Engineering College, Warangal, India aggregate portion and increasing the volume of paste and water-binder ratio.

Several research exploits have focussed on improving the self-compacting concrete features [1-6]. Thus, in the evolving technology, sustainability of the material is mostly desired. Lightweight aggregates such as those emanating from natural sources; pumice, scoria or artificial sources, industrial wastes, are being explored in SCC [7]. Recycled aggregates have also been tested as SCC ingredient [8-10]. The literatures showed that, based on the evaluation of workability and strength characteristics, the SCC produced with materials from the various sources performed somewhat similar to the normal SCC. Nanthagopala [11] recommended high volume paste, using manufactured sand, as aggregate for achieving the required flow in SCC. And while investigating the influence of dune sand aggregates in SCC, Khattab [12] reported that partial replacement of natural sand with sand dunes up to $50 \%$ resulted in improved compressive and flexural strengths of SCC. In another study [13], three different types of blended cement (binary, ternary and quaternary) of OPC, fly ash, silica fume, and GGBS, up to $60 \%$ were used to improve fresh properties of SCC made with recycled aggregates. It was shown from the study that blended cement improved the fresh properties of SCC, without any sign of segregation. 